Odessa State Environmental University, 15, Lvovskaya str., Odessa-16, 65016, Ukraine

E-mail: ternovskyev@gmail.com

\title{
RELATIVISTIC SPECTROSCOPY OF MULTICHARGED IONS IN PLASMAS: Li-LIKE IONS
}

\begin{abstract}
The transition probabilities and lifetimes for different excited states in spectrum of the Li-like calcium are computed within the consistent relativistic many-body approach for different values of the plasmas screening parameter (correspondingly, electron density and temperature) and compared with available alternative data. The approach is based on the generalized relativistic energy approach combined with the optimized relativistic many-body perturbation theory with the Dirac-Debye shielding model as zeroth approximation, adapted for application to study of the spectral parameters of ions in plasmas. An electronic Hamiltonian for N-electron ion in plasmas is added by the Yukawa-type electron-electron and nuclear interaction potential.
\end{abstract}

\section{Introduction}

The properties of laboratory, thermonuclear (tokamak), laser-produced, astrophysical plasmas have drawn considerable attention over the last decades [1-14]. It is known that multicharged ions play an important role in the diagnostics of a wide variety of plasmas [110]. Electron-ion collisions involving multiply charged ions, as well as various radiation and radiation-collisional processes, predetermine the quantitative characteristics of the energy balance of the plasmas [1-6,15-20]. For this reason, the plasmas modelers and diagnosticians require absolute cross sections for these processes. The cross sections for electron-impact excitation of ions are needed to interpret spectroscopic measurements and for simulations of plasmas using collisional-radiative models. The electron-ion collisions play a major role in the energy balance of plasmas. ([1-6]). Different theoretical methods were employed along with the Debye screening to study plasma medium. Earlier we have developed a new version of a relativistic energy approach combined with the many-body perturbation theory (RMBPT) for multi-quasiparticle (QP) systems to study spectra of plasma of the multicharged ions, electron-ion collisional parameters [15-20]. The method is based on the Debye shielding model and energy approach [21-23]. A new element of this paper is in using the effective optimized Dirac-Kohn-Sham method in general relativistic energy approach to collision processes in the Debye plasmas.

In this paper, which goes on our work [15-20], we present the results of computing the transition probabilities and lifetimes for different excited states in spectrum of the Lilike calcium for different values of the plasmas screening (Debye) parameter (respectively, electron density, temperature) and compared with available alternative spectroscopic data. The approach used is based on the generalized relativistic energy approach combined with the optimized RMBPT with the Dirac-Debye shielding model as zeroth approximation, adapted for application to study the spectral parameters of ions in plasmas. An electronic Hamiltonian for N-electron ion in plasmas is added by the Yukawa-type electron-electron and nuclear interaction potential.

\section{Optimized relativistic perturbation theory formalism for ions in plasmas}

The detailed description of our approach was earlier presented (see, for example, Refs. [15-20]). Therefore, below we are limited only by the key points. The generalized relativistic energy approach combined with the RMBPT has been in detail described in Refs. [6,24-29]. It 
generalizes earlier developed energy approach. The key idea is in calculating the energy shifts $\Delta E$ of degenerate states that is connected with the secular matrix $M$ diagonalization [6,24,25]. To construct $M$, one should use the Gell-Mann and Low adiabatic formula for $\Delta E$. The secular matrix elements are already complex in the PT second order. The whole calculation is reduced to calculation and diagonalization of the complex matrix $M$ and definition of matrix of the coefficients with eigen state vectors $B_{\dot{e}, \dot{v}}^{K}[6,25]$. To calculate all necessary matrix elements one must use the bases of the 1QP relativistic functions. Within an energy approach the total energy shift of the state is usually presented as [24]:

$$
\Delta \mathrm{E}=\operatorname{Re} \Delta \mathrm{E}+\mathrm{i} \Gamma / 2
$$

where $\Gamma$ is interpreted as the level width and decay (transition) possibility $P=\Gamma$. The imaginary part of electron energy of the system, which is defined in the lowest PT order as [6]:

$$
\begin{gathered}
\operatorname{mi} \Delta E(B)=-\frac{e^{2}}{4 \pi} \sum_{\substack{\alpha>n>f \\
[\alpha<n \leq f]}} V_{\alpha n \alpha n}^{\left|\omega_{\alpha n}\right|} \\
V_{i j k l}^{|\omega|}=\iint d r_{1} d r_{2} \Psi_{i}^{*}\left(r_{1}\right) \Psi_{j}^{*}\left(r_{2}\right) \frac{\sin |\omega| r_{12}}{r_{12}}\left(1-\alpha_{1} \alpha_{2}\right) \Psi_{k}^{*}\left(r_{2}\right) \Psi_{l}^{*}\left(r_{1}\right)
\end{gathered}
$$

where $\sum$ for electron and $\sum$ for vacancy. The separated terms of the sumprin (2) represent the contributions of different channels.

According to the definition, a lifetime of some excited state $\mathrm{f}$ is defined as follows (included all possible transition channels):

$$
\tau_{f}=1 / \sum_{A, i} P_{f-i}^{A}
$$

for the transition rate $P_{f-i}^{A}$ due to a radiative operator $\mathrm{A}$. The transition rates via various multipole channels are determined as follows:

$$
P_{f-i}^{E 1}=\frac{2.02613 \cdot 10^{18}}{\lambda^{3}\left(2 J_{f}+1\right)} S_{f-i}^{E 1}
$$

$$
\begin{aligned}
& P_{f-i}^{M 1}=\frac{2.69735 \cdot 10^{13}}{\lambda^{3}\left(2 J_{f}+1\right)} S_{f-i}^{M 1} \\
& P_{f-i}^{E 2}=\frac{1.11995 \cdot 10^{18}}{\lambda^{5}\left(2 J_{f}+1\right)} S_{f-i}^{E 2}
\end{aligned}
$$

where $\lambda$ is the wavelength $(\AA), J_{f}$ is the total angular momentum of the f state, $S_{f-i}^{A} \sim \operatorname{Im} \Delta \mathrm{E}$ is a line strength due to the corresponding transition operator A (the decay channels E1, M1 and E2 represent the electric dipole, magnetic dipole, and electric quadrupole transition channels respectively). It is known $[3,4,25]$ that the matrix elements computed with using the length gauge expressions converge faster than the velocity ones with respect to the configuration space of the orbital bases; the authors [3] considered the length gauge expressions for evaluating the foregoing transition properties.

This fact is directly linked with correct accounting for the correlation effects and using the optimized basis of wave functions. In [25] it has been proposed "ab initio" optimization principle for construction of cited basis. It uses a minimization of the gauge dependent multielectron contribution of the lowest QED PT corrections to the radiation widths of atomic levels. This contribution describes collective effects and it is dependent upon the electromagnetic potentials gauge (the gauge noninvariant contribution $\delta \mathrm{E}_{\text {ninv }}$ ). The minimization of $\operatorname{Im} \delta \mathrm{E}_{n i n v}$ leads to integral differential equation, that is numerically solved. In result one can get the optimal one-electron basis of the PT [24-26]. It is worth to note that this approach was used while solving multiple problems of modern atomic, nuclear and molecular physics (see [3038]).

Further let us firstly consider the Debye shielding model according to Refs. $[15,16]$. What is known from the classical theory of plasmas developed by Debye-Hückel, the interaction potential between two charged particles is modeled by the Yukawa-type potential, which contains the shielding parameter $\mu$. The parameter $\mu$ is connected with the plasma parameters such as 
the temperature $T$ and the charge density $\mathrm{n}$ as follows: $\quad \mu \sim \sqrt{e^{2}(1+Z) n_{e} / k_{B} T_{e}}$. Here, as usually, e is the electron charge and $\kappa_{b}$ is the Boltzman constant. The density $n$ is given as a sum of the electron density $N_{e}$ and ion density $N_{\mathrm{k}}$ of the $\mathrm{k}$-th ion species having the nuclear charge

$$
q_{k}: n=N_{e}+\sum_{k} q_{k}^{2} N_{k} .
$$

It is very useful to remind the simple estimates for the shielding parameter. For example, under typical laser plasmas conditions of $T \sim 1 \mathrm{keV}$ and $n \sim 10^{22} \mathrm{~cm}^{-3}$ the parameter $\mu$ is of the order of 0.1 in atomic units; in the EBIT plasmas $T \sim 0.05 \mathrm{keV}, n \sim 10^{18} \mathrm{~cm}^{-3}$ and $\mu \sim 10^{-3}$. We are interested in studying the spectral parameters of ions in plasmas with the temperature $T \sim 0.1-1 \mathrm{keV}\left(10^{6}-10^{7} \mathrm{~K}\right)$ and $n \sim 10^{14}-10^{26} \mathrm{~cm}^{-3} \quad\left(\mu \sim 10^{-5}-10^{0}\right)$. It should be noted that indeed the Debye screening for the atomic electrons in the Coulomb field of nuclear charge is well understood due to the presence of the surrounding plasma electrons with high mobility. On the other hand, the contribution due to the Debye screening between electrons would be of smaller magnitude orders. Majority of the previous works on the spectroscopy study have considered the screening effect only in the electron-nucleus potential where the electronelectron interaction potential is truncated at its first term of the standard exponential expansion for its dominant contribution [3]. However, it is also important to take into account the screening in the electron- electron interactions for large plasma strengths to achieve more realistic results in the search for stability of the atomic structure in the plasma environment.

By introducing the Yukawa-type e-N and e-e interaction potentials, an electronic Hamiltonian for $\mathrm{N}$-electron ion in a plasma is in atomic units as follows $[15,16]$ :

$$
\begin{gathered}
H=\sum_{i}\left[\alpha c p-\beta m c^{2}-Z \exp \left(-\mu r_{i}\right) / r_{i}\right]+ \\
+\sum_{i>j} \frac{\left(1-\alpha_{i} \alpha_{j}\right)}{r_{i j}} \exp \left(-\mu r_{i j}\right)
\end{gathered}
$$

To generate the wave functions basis we use the optimized Dirac-Kohn-Sham potential with one parameter [15], which is calibrated within the special ab initio procedure within the relativistic energy approach [24]. The modified PC numerical code 'Superatom" is used in all calculations. Other details can be found in Refs. $[15-20,22,23,38]$.

\section{Results and conclusion}

Firstly, we present our results on the transition probabilities and lifetimes for some excited states of the Li-like ion of calcium. The spectroscopic properties for plasma-isolated ion with $\mu=0$ have been considered. In Tables 1 and 2 there are listed probabilities values for transitions (E1, M1, and E2 channels) from the excited states to the low-lying states of Ca XVIII. Using these values, one could calculate the corresponding lifetimes of the excited states.

Table 1.

The transition probabilities (P) for some transitions in spectrum of Ca XVIII: RCC - relativistic coupled-cluster (RCC) method [3]; This - this work

\begin{tabular}{|c|c|c|}
\hline \multicolumn{1}{|c|}{ Transition } & $P_{f \rightarrow i}$ & $P_{f \rightarrow i}$ \\
\hline$f-i$ & $\mathrm{RCC}$ & This \\
\hline $2 \mathrm{p}_{1 / 2}-(\mathrm{E} 1)-2 \mathrm{~s}_{1 / 2}$ & $1.31[9]$ & $1.33[9]$ \\
\hline $2 \mathrm{p}_{3 / 2}-(\mathrm{E} 1)-2 \mathrm{~s}_{1 / 2}$ & $2.00[9]$ & $2.02[9]$ \\
\hline$-(\mathrm{M} 1)-2 \mathrm{p}_{1 / 2}$ & $7.00[2]$ & $7.03[2]$ \\
\hline$-(\mathrm{E} 2)-2 \mathrm{p}_{1 / 2}$ & $2.54[-2]$ & $2.57[-2]$ \\
\hline $3 \mathrm{~s}_{1 / 2}-\mathrm{M} 1-2 \mathrm{~s}_{1 / 2}$ & $2.04[4]$ & $2.06[4]$ \\
\hline$-(\mathrm{E} 1)-2 \mathrm{p}_{1 / 2}$ & $3.01[11]$ & $3.02[11]$ \\
\hline$-(\mathrm{E} 1)-2 \mathrm{p}_{3 / 2}$ & $6.22[11]$ & $6.24[11]$ \\
\hline
\end{tabular}

The analysis shows that the presented data are in physically reasonable agreement with the NIST experimental data and theoretical 
Table 2.

The transition probabilities (P) for some transitions in spectrum of Ca XVIII (our data)

\begin{tabular}{|c|c|}
\hline Transition & $P_{f \rightarrow i}$ \\
\hline$f-i$ & This \\
\hline $3 \mathrm{p}_{1 / 2}-\mathrm{E} 1-2 \mathrm{~s}_{1 / 2}$ & $2.37[12]$ \\
\hline$-\mathrm{M} 1-2 \mathrm{p}_{1 / 2}$ & $1.48[3]$ \\
\hline$-\mathrm{M} 1-2 \mathrm{p}_{3 / 2}$ & $6.78[4]$ \\
\hline$-\mathrm{E} 2-2 \mathrm{p}_{3 / 2}$ & $8.45[8]$ \\
\hline$-\mathrm{E} 1-3 \mathrm{~s}_{1 / 2}$ & $1.72[8]$ \\
\hline $3 \mathrm{p}_{3 / 2}-\mathrm{E} 1-2 \mathrm{~s}_{1 / 2}$ & $2.32[12]$ \\
\hline$-\mathrm{M} 1-2 \mathrm{p}_{1 / 2}$ & $1.24[4]$ \\
\hline$-\mathrm{E} 2-2 \mathrm{p}_{3 / 2}$ & $4.25[8]$ \\
\hline$-\mathrm{M} 1-2 \mathrm{p}_{3 / 2}$ & $2.78[4]$ \\
\hline$-\mathrm{E} 2-2 \mathrm{p}_{3 / 2}$ & $4.22[8]$ \\
\hline$-\mathrm{E} 1-3 \mathrm{~s}_{1 / 2}$ & $2.66[8]$ \\
\hline$-\mathrm{M} 1-3 \mathrm{p}_{1 / 2}$ & $1.83[1]$ \\
\hline$-\mathrm{E} 2-3 \mathrm{p}_{1 / 2}$ & $2.13[-3]$ \\
\hline
\end{tabular}

\begin{tabular}{|l|l|l|}
\hline 0.133 & 741 & 738 \\
\hline 0.667 & 494 & 492 \\
\hline 1.000 & 334 & 332 \\
\hline 1.250 & 242 & 241 \\
\hline 1.429 & 192 & 190 \\
\hline 0.60 & 140 & 138 \\
\hline
\end{tabular}

Table 4.

The dependence of the lifetimes (ps) of the 3lj,4lj states in the Ca XVIII spectrum upon the parameter $\mu$ (this work)

\begin{tabular}{|c|c|c|c|c|}
\hline$\mu$ & $3 \mathrm{~s}_{1 / 2}$ & $3 \mathrm{p}_{1 / 2}$ & $3 \mathrm{~d}_{3 / 2}$ & $4 \mathrm{~s}_{1 / 2}$ \\
\hline 0.133 & 1.07 & 0.428 & 0.143 & 1.62 \\
\hline 0.667 & 1.26 & 0.518 & 0.688 & 2.54 \\
\hline 1.000 & 1.53 & 0.658 & 0.206 & 4.81 \\
\hline 1.250 & 1.85 & 0.849 & 0.262 & 12.48 \\
\hline 1.429 & 2.20 & 1.072 & 0.336 & 82.77 \\
\hline
\end{tabular}

approach with different forms of transition operator (i.e. using the photon propagators in the results by relativistic coupled-cluster (RCC) method calculation [3]. However, some difference between the corresponding results can be explained by using different relativistic orbital bases and by difference in the model of accounting for the screening effect as well as some numerical differences. In Tables 3 and 4 we list the numerical variations in the lifetimes of the $2 p_{1 / 2}$, $3 s_{1 / 2}, 3 p_{1 / 2}, 3 d_{3 / 2}$, and $4 s_{1 / 2}$ states in Ca XVIII for different $\mu$ values. It is worth to note that our computing oscillator strengths within energy

Table 3.

The dependence of the lifetimes (ps) of the $2 p_{1 / 2}$ state in the Ca XVIII spectrum upon the screening parameter $\mu$ : $\mathrm{RCC}$ - relativistic coupled-cluster (RCC) method [3]; This - this work

\begin{tabular}{|c|c|c|}
\hline$\mu$ & $2 \mathrm{p}_{1 / 2}$ & $2 \mathrm{p}_{1 / 2}$ \\
\hline & RCC & This \\
\hline
\end{tabular}

form of Coulomb, Feynman or Babushkin) gives very close results.

\section{References}

1. Yongqiang, Li Y., Wu, J., Hou, Y., Yuan, J. Influence of hot and dense plasmas on energy levels and oscillator strengths of ions: Be-like ions for $Z=26-36, J$. Phys. B: At. Mol. Opt. Phys. 2008, 41, 145002.

2. Saha B., Fritzsche S. Influence of dense plasma on the low-lying transitions in Belike ions: relativistic multiconfiguration Dirac-Fock calculation. J. Phys. B: At. Mol. Opt. Phys. 2007, 40, 259-270.

3. Madhulita Das, Sahoo B. K., Sourav Pal. Relativistic spectroscopy of plasma embedded Li-like systems with screening effects in two-body Debye potentials. J. Phys. B: At. Mol. Opt. Phys. 2014, 47, 175701.

4. Han, Y.-C., Madsen, L.B. Comparison between length and velocity gauges in quantum simulations of high-order harmonic 
generation Phys. Rev. A. 2010, 81, 06343.

5. Glushkov, A.V., Khetselius, O.Yu., Svinarenko, A.A., Buyadzhi, V.V., Spectroscopy of autoionization states of heavy atoms and multiply charged ions. TEC: Odessa, 2015.

6. Ivanov, L.N., Ivanova, E.P., Aglitsky, E. Modern trends in the spectroscopy of multicharged ions. Phys. Rep. 1988, 166.

7. Bandrauk, A.D., Fillion-Gourdeau, F., Lorin, E. Atoms and molecules in intense laser fields: gauge invariance of theory and models J. Phys. B: At. Mol. Opt. Phys. 2013, 46, 153001

8. Glushkov, A.V., Malinovskaya, S.V., Prepelitsa, G.P., Ignatenko, V. Manifestation of the new laser-electron nuclear spectral effects in the thermalized plasma: QED theory of co-operative laser-electron-nuclear processes. J. Phys.: Conf. Ser. 2005, 11, 199206.

9. Gubanova, E., Glushkov, A.V., Khetselius, O.Yu., Bunyakova, Yu.Ya., Buyadzhi, V.V., Pavlenko, E.P. New methods in analysis and project management of environmental activity: Electronic and radioactive waste. FOP: Kharkiv, 2017.

10. Glushkov, A.V., Malinovskaya, S.V., Chernyakova Y.G., Svinarenko, A.A. Cooperative laser-electron-nuclear processes: QED calculation of electron satellites spectra for multi-charged ion in laser field. I. $J$. Quant. Ch. 2004, 99, 889.

11. Glushkov, A., Malinovskaya, S., Loboda, A., Shpinareva, I., Gurnitskaya, E., Korchevsky, D. Diagnostics of the collisionally pumped plasma and search of the optimal plasma parameters of $\mathrm{x}$-ray lasing: calculation of electron-collision strengths and rate coefficients for Ne-like plasma. J. Phys.: Conf. Ser. 2005, 11, 188-198.

12. Glushkov, A., Ambrosov, S., Loboda, A., Gurnitskaya, E., Prepelitsa, G. Consistent QED approach to calculation of electroncollision excitation cross sections and strengths: Ne-like ions. Int. J. Quant. Chem. 2005, 104, 562-569.

13. Ignatenko, A.V. Probabilities of the radiative transitions between Stark sublevels in spectrum of atom in an DC electric field:
New approach. Photoelectronics, 2007, 16, 71-74.

14. Glushkov, A.V., Ambrosov, S.V., Ignatenko, A. Non-hydrogenic atoms and Wannier-Mott excitons in a DC electric field: Photoionization, Stark effect, Resonances in ionization continuum and stochasticity. Photoelect., 2001, 10, 103.

15. Buyadzhi, V., Kuznetsova, A., Buyadzhi, A., Ternovsky, E.V., Tkach, T.B. Advanced quantum approach in radiative and collisional spectroscopy of multicharged ions in plasmas. Adv. in Quant. Chem. (Elsevier). 2019, 78, 171-191,

16. Glushkov, A., Buyadzhi, V., Svinarenko, A., Ternovsky, E. Advanced relativistic energy approach in electron-collisional spectroscopy of multicharged ions in plasma. Concepts, Methods, Applications of Quantum Systems in Chemistry and Physics (Springer). 2018, 31, 55-69.

17. Buyadzhi, V.V., Chernyakova, Yu.G., Smirnov, A.V., Tkach, T.B. Electron-collisional spectroscopy of atoms and ions in plasma: Be-like ions. Photoelectronics. 2016, 25, 97-101.

18. Buyadzhi, V.V., Chernyakova, Yu.G., Antoshkina, O.A., Tkach, T.B. Spectroscopy of multicharged ions in plasmas: Oscillator strengths of Be-like ion Fe. Photoelectronics. 2017, 26, 94 ..

19. Buyadzhi, V. Laser multiphoton spectroscopy of atom embedded in Debye plasmas: multiphoton resonances and transitions. Photoelectronics. 2015, 24, 128-133.

20. Buyadzhi, V., Zaichko, P., Antoshkina, O., Kulakli T., Prepelitsa P., Ternovsky V., Mansarliysky, V. Computing of radiation parameters for atoms and multicharged ions within relativistic energy approach: Advanced Code. J. Phys.: Conf. Ser. 2017, 905(1), 012003.

21. Glushkov, A., Svinarenko, A., Ignatenko, A. Spectroscopy of autoionization resonances in spectra of the lanthanides atoms. Photoelectronics. 2011, 20, 90-94.

22. Glushkov, A.V. Relativistic Quantum theory. Quantum mechanics of atomic systems; Astroprint: Odessa, 2008. 
23. Khetselius, O.Yu. Hyperfine structure of atomic spectra. Astroprint: Odessa, 2008.

24. Glushkov, A., Ivanov, L., Ivanova, E.P. Autoionization Phenomena in Atoms. Moscow Univ. Press, Moscow, 1986, 58.

25. Glushkov, A.V., Ivanov, L.N. Radiation decay of atomic states: atomic residue polarization and gauge noninvariant contributions. Phys. Lett.A. 1992, 170, 33.

26. Glushkov, A.V. Spectroscopy of atom and nucleus in a strong laser field: Stark effect and multiphoton resonances. J. Phys.: Conf. Ser. 2014, 548, 012020.

27. Glushkov, A., Svinarenko, A., Ternovsky, V., Smirnov, A., Zaichko, P. Spectroscopy of the complex autoionization resonances in spectrum of helium: Test and new spectral data. Photoelectr. 2015, 24, 94.

28. Glushkov A.V.; Ivanov, L.N. DC strongfield Stark effect: consistent quantum-mechanical approach. J. Phys. B: At. Mol. Opt. Phys. 1993, 26, L379-386.

29. Khetselius, O.Yu. Quantum structure of electroweak interaction in heavy finite Fermi-systems. Astroprint: Odessa, 2011.

30. Khetselius, O.Yu., Lopatkin, Yu.M., Dubrovskaya, Yu.V, Svinarenko, A.A. Sensing hyperfine-structure, electroweak interaction and parity non-conservation effect in heavy atoms and nuclei: New nuclear-QED approach. Sensor Electr. and Microsyst. Techn. 2010, 7(2), 11-19.

31. Khetselius, O.Yu. Relativistic perturbation theory calculation of the hyperfine structure parameters for some heavy-element isotopes. Int. J. Quant. Chem. 2009, 109, 3330-3335.

32. Khetselius, O. Relativistic calculation of the hyperfine structure parameters for heavy elements and laser detection of heavy isotope. Phys. Scr. 2009, 135, 01402

33. Svinarenko, A.A., Glushkov, A.V., Khetse- lius, O.Yu., Ternovsky, V.B., Dubrovskaya, Yu., Kuznetsova, A., Buyadzhi, V. Theoretical spectroscopy of rare-earth elements: spectra and autoionization resonances. Rare Earth Element, Ed. J.Orjuela (InTech). 2017, 83.

34. Glushkov, A.V., Khetselius, O.Yu., Svinarenko, A.A., Buyadzhi, V.V., Ternovsky, V.B, Kuznetsova, A., Bashkarev, P Relativistic perturbation theory formalism to computing spectra and radiation characteristics: application to heavy element. Recent Studies in Perturbation Theory, InTech. 2017, 131.

35. Dubrovskaya, Yu., Khetselius, O.Yu., Vitavetskaya, L., Ternovsky, V., Serga, I. Quantum chemistry and spectroscopy of pionic atomic systems with accounting for relativistic, radiative, and strong interaction effects. Adv. Quantum Chem. 2019, 78, 193-222.

36. Khetselius, O.Yu., Glushkov, A.V., Dubrovskaya, Yu.V., Chernyakova, Yu.G., Ignatenko, A.V., Serga, I.N., Vitavetskaya, L. Relativistic quantum chemistry and spectroscopy of exotic atomic systems with accounting for strong interaction effects. In Concepts, Methods and Applications of Quantum Systems in Chem. and Phys. Springer. 2018, 31, 71.

37. Glushkov, A., Buyadzhi, V., Kvasikova, A., Ignatenko, A., Kuznetsova, A., Prepelitsa, G., Ternovsky, V. Non-Linear chaotic dynamics of quantum systems: Molecules in an electromagnetic field and laser systems. In: Tadjer A, Pavlov R, Maruani J, Brändas E, Delgado-Barrio G (eds) Quantum Systems in Physics, Chemistry, and Biology. Springer, Cham. 2017, 30, 169-180.

38. Glushkov, A.V., Khetselius, O.Yu., Svinarenko, A.A., Buyadzhi, V.V., Methods of computational mathematics and mathematical physics. P.1.TES: 2015. 
PACS 31.15.-p

E. V. Ternovsky

\title{
RELATIVISTIC SPECTROSCOPY OF MULTICHARGED IONS IN PLASMAS: Li-LIKE IONS
}

Summary. The transition probabilities and lifetimes for different excited states in spectrum of the Li-like calcium are computed within the consistent relativistic many-body approach for different values of the plasmas screening parameter (correspondingly, electron density and temperature) and compared with available alternative data. The approach is based on the generalized relativistic energy approach combined with the optimized relativistic many-body perturbation theory with the Dirac-Debye shielding model as zeroth approximation, adapted for application to study of the spectral parameters of ions in plasmas. An electronic Hamiltonian for N-electron ion in plasmas is added by the Yukawa-type electron-electron and nuclear interaction potential.

Key words: spectroscopy of ions in plasmas, relativistic energy approach, radiative transition probabilities

PACS 31.15.-p

\section{Е. В. Терновский}

\section{РЕЛЯТИВИСТСКАЯ СПЕКТРОСКОПИЯ МНОГОЗАРЯДНЫХ ИОНОВ В ПЛАЗМЕ: Li-ПОДОБНЫЕ ИОНЫ}

Резюме. Вероятности переходов и времена жизни для различных возбужденных состояний в спектре Li-подобного кальция вычисляются в рамках последовательного релятивистского многочастичного подхода для различных значений параметра экранирования плазмы (соответственно, электронной плотности и температуры) и сравниваются с имеющимися альтернативными данными. Подход основан на обобщенном релятивистском энергетическом подходе, совмещенном с формализмом оптимизированной релятивистской многочастичной теории возмущений с приближением Дирака-Дебая в качестве нулевого приближения, адаптированной для применения при изучении спектральных параметров ионов в плазме. Электронный гамильтониан для иона $\mathrm{N}$-электронов в плазме добавляется потенциалом электрон-электронного и ядерного взаимодействия типа Юкавы.

Ключевые слова: спектроскопия ионов в плазме, энергетический подход, вероятности радиационных переходов

PACS 31.15.-p

\author{
С В. Терновський
}

\section{РЕЛЯТИВІСТСЬКА СПЕКТРОСКОПІЯ БАГАТОЗАРЯДНИХ ІОНІВ В ПЛАЗМІ: Lі-ПОДІБНІ ІОНИ}

Резюме. Ймовірності переходів і часи життя для різних збуджених станів в спектрі Liподібного кальцію обчислюються в рамках послідовного релятивістського багаточастинко- 
вого підходу для різних значень параметра екранування плазми (відповідно, електронної щільності і температури) і порівнюються з наявними альтернативними даними. Підхід грунтується на узагальненому релятивістському енергетичному підході, поєднаному з формалізмом оптимізованої релятивістської багаточастинкової теорії збурень $з$ наближенням Дірака-Дебая в якості нульового наближення, адаптованого для застосування при вивченні спектральних параметрів іонів у плазмі. Електронний гамільтоніан для іона $\mathrm{N}$-електронів в плазмі додається потенціалом електрон-електронного та ядерного взаємодії типу Юкави.

Ключові слова: спектроскопія іонів в плазмі, енергетичний підхід, ймовірності радіаційних переходів 